\title{
Our Conceptions of the Processes of Heredity.*
}

\author{
By Miss E. R. Saunders, F.L.S.
}

II.

THE behaviour of the sex-chromosomes as here outlined suffices to account for the occurrence of sex-linked inheritance, but the relations found to hold between one sex-linked character and another need further explanation. If a cross is made involving two sex-linked characters, the $F_{1}$ females when tested by a double recessive male are found to produce the expected four classes of gametes, but not in equal proportions, or in the same proportions in the case of different pairs of sex-linked characters. Partial linkage (coupling) occurs of the kind which has already been described for the stock and the sweet pea. The parental combinations predominate, the recombinations ("cross-overs") comprise the smaller categories. The strength of the linkage varies, however, for different characters, but is found to be constant for any given pair. Since the sex-linked factors are by hypothesis carried in the sex-chromosomes, a clean separation of homologous members at meiosis should result in the characters which were associated in the parents remaining strictly in the same combination in each succeeding generation. The fact that this is not the case has led Morgan to conclude that an interchange of chromosome material must take place at this phase among a proportion of the gametes, and that the percentage of these "crossovers" will depend on the distance apart of the loci of the factors concerned. This phenomenon of linkage may also be exhibited by pairs of characters which show no sex-linkage in their inheritance. The factors involved in these latter cases must presumably, therefore, be disposed in one of the chromosomes which is not the sex-chromosome.

To this brief sketch of the main points of Morgan's chromosome theory must be added mention of the extremely interesting relation which lends strong support to his view, and the significance of which seems scarcely to admit of question, viz. that in Drosophila ampelophila there are four pairs of chromosomes, and that the linkage relations of the hundred and more characters investigated indicate that they form four distinct groups. It is scarcely possible to suppose that the one fact is not directly connected with the other. The interesting discovery of Bridges (Journ. Exper. Zool., vol. xv., I9I3) that the appearance of certain unexpected categories among Drosophila offspring, where females of a particular strain were used, coincided with the presence in these females of an additional chromosome adds another link in the chain of evidence. On examination it was found that in these females the $\mathrm{X}$ chromosome pair occasionally failed to separate at the reduction division, and, consequently, that the two XX chromosomes sometimes both remained in the egg, and sometimes both passed out into the polar body. Hence there arose from fertilisation of the XX eggs some individuals containing three sex-chromosomes, with the resulting upset of the expectation in regard to sexlimitation of characters which was observed.

It, however, remains a curious anomaly that in the cross-bred Drosophila male no corresponding crossing-over of linked characters, whether associated with the sex-character or not, has yet been observed. His gametes carry only the same factorial combinations which he received from his parents. For this

* From the npening address of the President of Section $\mathrm{K}$ (Botany) delivered at the Cardiff meeting of the British Association on August 24 . No. 2660 , VOL. I06] contrast in the behaviour between the sexes there is at present no explanation. The reverse condition has been described by Tanaka (Journ. Coll. Agr., Sapporo, Japan, I913-14) in the silkworm. Here interchange takes place in the male, but not in the female.

It must, then, be acknowledged that Morgan's interpretation of the cytological evidence has much in its favour. The striking parallel between the behaviour of the chromosomes and the distributional relations of Mendelian allelomorphs is obvious. The existence in Drosophila ampelophila of four pairs of chromosomes and of four sets of linked characters can scarcely be mere coincidence. The employment of the smaller physical unit in accounting for the reshuffling of characters in their transmission commends itself in principle. The necessity for postulating the occurrence of some orderly irregularity in the hereditary process in order to explain the phenomenon of partial linkage is, it will be seen, inherent alike in both theories. When, however, we come to examine the general applicability of Morgan's theory, we are confronted with a considerable body of facts among plants which we find difficult to reconcile with the requirement that factorial segregation is accomplished by means of the reduction division. An instance in which this is particularly clearly indicated is that of the sulphur-white stock. I have chosen this example because here we have to do with two characters which are distinguished with the utmost sharpness, viz. plastid colour and flower form. The peculiar behaviour of this strain is due to the fact that not only are the two factors for flower form (singleness and doubleness) differently distributed to the male and female sides of the individual, as in all double-throwing stocks, but the factor controlling plastid colour likewise shows linkage with the sexnature of the germ-cells. As a result every individual, even though self-fertilised, yields a mixed offspring, consisting chiefly of single whites and double creams, but including a small percentage of double whites. So far as the ovules are concerned, the mode of inheritance can be accounted for on either theory. According to the reduplication hypothesis, the factors $\mathrm{XY}$, producing singleness, and $\mathrm{W}$, giving white plastids, are partially coupled so as to give the gametic ratio on the female side 7 WXY: I WXy :

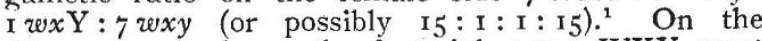
chromosome scheme the factorial group WXY must be assumed to be disposed in one member of the bivalent chromosome formed at meiosis, the corresponding recessive allelomorphs wxy in the other. If the three factors be supposed to be arranged in the chromosome in alphabetical order, and if, on separation, a break take place between the loci of the two factors for flower form (as shown), so as to give "cross-overs" of $\mathrm{Y}$ and $y$ in about 12 per cent. of the gametes, the occurrence of such "cross-overs" would fulfil the required conditions. But the case of the pollen presents a distinct difficulty on this latter view. The sulphurwhite stock is distinguished from both the Drosophila and the Abraxas type by the fact that none of the male germs carry either of the dominant characters. In Dlace of the XX-XY form of sex-linked inheritance in the former type and the WZ--ZZ in the latter, we should need to regard this form as constituting a new class, which we might represent as DR-RR, thus indicating that both members of the bivalent chromo-

1 The letters $\mathrm{X}$ and $\mathrm{Y}$ are used here to denote particular factors, not, as in Morgan's scheme, the entire sex-chromosome. 
some on the male side appear to be inert and able to carry only the recessive characters, and hence are represented as $R R$, in contrast with the $D R$ pair of the female side. By this formula we can indicate the behaviour of the several double-throwing strains. It is, besides, becoming clear, I think, from recent results that there is no "crossing-over" of these factors on the male side in the $F_{1}$ cross-breds. But the real difficulty is to explain why these factors are confined to the female side in the ever-sporting individual. This may result from aberrant behaviour or from loss of chromosomes at some point in pollen development. On this point I hope that evidence will shortly be available. Failing such evidence, the presumption is that the elimination of XY (and in one strain of $\mathrm{W}$ ) must have taken place prior to, and not at, the moment of the maturation division. Morgan's proposal to fit the pollen into his scheme for Drosophila by having recourse to hypothetical lethal factors does not appeal to the observer, who finds the pollen all uniformly good and every ovule set. Other examples suggesting premeiotic segregation can be quoted, notably cases among variegated plants and plants showing bud sports, where somatic segregation appears to be of regular occurrence.

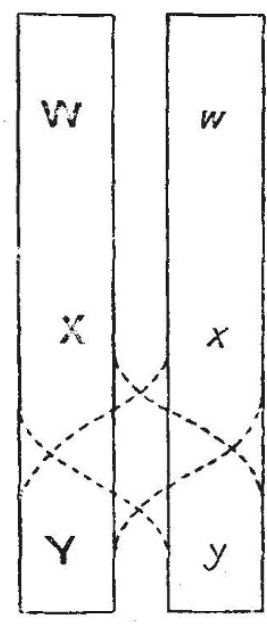

Ovules

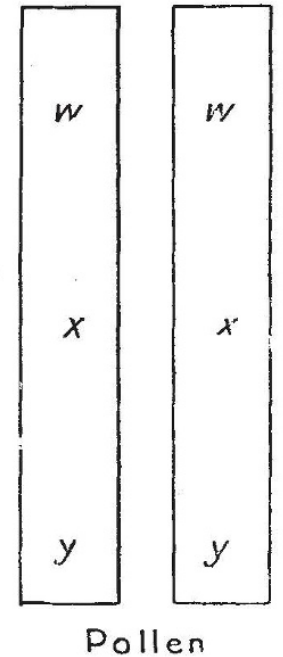

It has been argued from time to time that any scheme representing the mechanism of heredity which leaves out of account the cytoplasm must prove inadequate. This general statement has been expressed in more definite form by Loeb ("The Organism as a Whole," I9I6), who holds that the egg cytoplasm is to be looked upon as determining the broad outlines-in fact, as standing for the embryo "in the rough," upon which are impressed in the course of development the characteristics controlled by the factors segregated in the chromosomes. The arguments in favour of the view that the cytoplasm, apart from its general functions in connection with growth and nutrition, is the seat of a particular hereditary process are mainly derived from observation upon embryonic characters in certain animals, chiefly Echinoderms, where the inheritance appears to be purely maternal. It has been shown, however, that such female prepotency is no indication that inheritance. of the determining factors takes place through the cytoplasm. Other causes may lead to this result. It has been observed, for example, that hybrid sea-urchin larvæ, which at one season of the year were maternal in type, at another were all raternal in character, showing that the result was No. 2660, VOL. IO6] due to some effect of the environment. Again, where the hybrid plutei showed purely maternal characters it was discovered by Baltzer (Archiv für Zellforschung, vol. v., I910) that in the earliest mitoses of the crossfertilised eggs a certain number of chromosomes fail to reach the poles, and are, consequently, left out of the daughter nuclei. The chromosomes thus lost probably represent those contributed by the male gamete, for in both parents certain individual chromosomes can be identitied owing to differences in shape and size. After this process of elimination, those characteristir of the male parent could not be traced, whereas the one pair distinctive of the female parent was still recognisable. In the reciprocal cross where the first mitosis follows a normal course the embryos are intermediate in regard to the character of the skeleton, thus affording proof of the influence of the male parent. Another type of case is found in the silkworm. Here a certain rate-character determining the time of hatching out of the eggs has been shown to exhibit normal Mendelian inheritance, the appearance that it is transmissible by the female through the cytoplasm alone being delusive. The eggs are always laid in the spring. According as they hatch out immediately so that a second brood is obtained in the year or do not hatch out for twelve months, the female parent laying the eggs is described as bivoltin or univoltin. Now the length of interval before hatching is obviously an egg-character, and therefore maternal in origin. Consequently, when a cross is made between a univoltin female and a bivoltin male the eggs laid are not cross-bred in respect of this character, any more than the seed formed as a result of a cross is cross-bred in respect of its seed-coat, which is a maternal structure. The silkworm mother being univoltin, the eggs will not hatch out until the following spring. The $F_{1}$ mother will, in turn, lay eggs which again take twelve months to hatch, since the long-period factor is the dominant. It is not until the eggs of the $F_{2}$ generation are laid that we see the expression of the character introduced by the bivoltin father. For some of the egg batches hatch at once, others not for twelve months, showing that of the $\mathrm{F}_{2}$ females some were univoltin and some bivoltin, and hence that the egg-character in any generation depends upon both the maternal and the paternal antecedents of the female producing the eggs.

Consequently, in the case of an egg-character the effects of inheritance must be looked for in the generation succeeding that in which the somatic characteristics of the zygote become revealed. We find, in fact, that in almost all instances where the evidence is suggestive of purely cytoplasmic inheritance, fuller investigation has shown that the explanation is to be found in one of the causes here indicated. The case of some plants where it has been established that reciprocal hybrids are dissimilar still however, remains to be cleared up. We know nothing as yet of the cytology of these cases, and it is not improbable that the interpretation may be found in some aberrant behaviour of the chromosomes. An instance in a plant type where a definite connection appears traceable between chromosome behaviour and somatic appearance has been recently emphasised by Gates (New Phytologist, vol. xix., 1920), who attributes the peculiarity of the lata mutation in Enothera (which has arisen as a modification at different times from each of three distinct species) to an irregularity in meiosis in the germ mother-cells whereby one daughter-cell receives an extra dunlicate chromosome which is lacking in the sister-cell. The cell with the extra chromosome fertilised by a normal germ produces a lata individual. On the chromosome view every normal fertilised egg contains a double 
set of chromosomes, each carrying a complete set of the factor elements. Hence, if some of the one set become eliminated, we can still imagine that a normal, though undersized, individual might develop. The converse relation, where increased size goes with multiplication of chromosomes, was discovered by Gregory (Proc. Roy. Soc., B, vol. Ixxxvii., rgi4) in a Primula, and occurs also in Enothera gigas, a mutant derived from $C E$. Lamarckiana. it is interesting in this connection to recall the results obtained by Nemec (Jahrb. f. wiss. Bot., xxxix., 1904, "Das Problem der Begruchtungsvorgänge," I910) as the result of subjecting the root-tips of various plants to the narcotising action of chloral hydrate. Under this treatment cells undergoing division at the time were able to form the daughter nuclei, but the production of a new cell-wall was inhibited. The cells thus became binucleate. If on recovery these cells were to fuse before proceeding to divide afresh a genuine tetraploid condition would result. So few cases of natural tetraploidy have thus far been observed that we have as yet no clue to the cause which leads to this condition.

The conclusions to which we are led by the considerations which have here been put forward are, in the main, that we have no warrant in the evidence so far available for attributing special hereditary processes to the cytoplasm as distinct from the nucleus. On the other hand, there is a very large body of facts pointing to a direct connection between phenotypic appearance and chromosomal behaviour. In animals the evidence that the chromosomes constitute the distributional mechanism may be looked upon as almost tantamount to proof; in plants the observations on Drosera, Primula, CEnothera, and Sphærocarpus are in harmony with this view. When we come, however, to the question of linkage and general applicability of the conception of "crossing-over" as adopted by Morgan and his school, we are on less certain ground. In Drosophila itself, the case which the scheme was framed to fit, the entire absence of "crossing-over" in the male remains unaccounted for, while the evidence from certain plant types appears to be definitely at variance with one of its fundamental premises. If segregation at the recognised reduction division is definitely established for animal types, then we must conclude that the sortingout process may follow a different course in the plant.

The question as to what is the precise nature of the differences for which the Mendelian factors stand is constantly before the mind of the breeder, but we are only now on the threshold of investigation in this direction, and it is doubtful whether we can as yet give a certain answer in any single instance. Still less are we able to say what the actual elements or units which undergo segregation may be. In the case of such allelomorphic pairs as purple and red sap colour or white or cream plastid colour, it may be that the difference is wholly qualitative, consisting merely in the formation or non-formation of some one chemical substance. But the majority of characteristics are not of this hard-and-fast type. Between some the distinction appears to be one of range-to be quantitative rather than, or as well as, qualitative in nature, and range must mean, presumably, either cumulative effect or a force or rate differerce. It mav well be, for example, that with some change in physiological equilibrium accompanying growth and development, factorial action mav be enhanced or accelerated, or, on the other hand, retarded or even inhibited altogether, and a regional grading result in consequence. Range in a character is not confined to, though a common characteristic of, individuals of No. 2660 , VOL. IO6] cross-bred origin. It may be a specific feature, both constant and definite in nature. For example, a change as development proceeds from a glabrous or nearly glabrous to a hairy condition is not an unusual occurrence in plants. In the stock such a gradational assumption of hairiness is apparent no less in the homozygous form containing a certain weak allelomorph controlling surface character, when present with the factors for sap colour, than in those heterozygous for this or some other essential component. We see a similar transition in several members of the Scrophulariaceæ, e.g. in various species of Digitalis, in Antirrhinum majus, $A$. orontium, Anarrhinum pedatum, Pentstemon, and Nemesia. In perennials an annual recurrence of this change of phase may be seen, as in various species of Viola and in Spiraea ulmaria. In some, perhaps in all, of these cases the allelomorphs may stand for certain states of physiological equilibrium, or such states may be an accompanying feature of factorial action. A change of phase may mean an altered balance, a difference of rhythm in interdependent physiological processes. In the case, for instance, of a certain sub-glabrous strain of stock in which the presence of a single characteristically branched hair or hairtuft over the water-gland terminating the midrib in a leaf otherwise glabrous is an hereditary character, it is scarcely conceivable that there is a localisation in this region of a special hair-forming substance. It seems more probable that some physiological condition intimately connected with the condition of watercontent at some critical period is a causal factor in hair production, and that this condition is set up over the whole leaf in the type, but in the particular strain in question is maintained only at the point which receives the largest and most direct supply. In this same strain a leaf may now and again be found lacking this hydathode trichome in an otherwise continuous hair-forming series, an occurrence which may well result from a slight fluctuation in physiological equilibrium such as is inherent in all vital processesa fluctuation which, when the genetic indicator is set so near to the zero point, may well send it off the scale altogether. If, as is not improbable in this and similar cases, we are concerned with a complex chain of physiological processes, investigation of the nature of the differenoes for which the allelomorphs stand may present a more difficult problem than where the production of a particular chemical compound appears to be involved. In such a physiological conception we have probably the explanation of the non-appearance of the recessive character in certain dominant crossbreds.

Up to this point we have treated of the organism from the aspect of its being a wholly self-controlled, independent system. As regards some characteristics, this may be regarded as substantially the case-that is to say, the soma reflects under all observed conditions the genetic constitution expressed in the Mendelian formula. Correspondence is precise between genotypic potentiality and phenotypic reality, and we have so far solved our problem that we can predict certainly and accuratelv the appearance of offspring, knowing the constitution of the parents. In such cases we may say that the efficiency of the genetic machine works out at roo per cent., the influence of external environment at o. Our equation somatic appearance $=$ factorial constitution requires no correction for effect of conditions of temperature, humiditv, illumination, and the like. But most somatic characters show some degree of variability. Phenotvpic appearance is the outcome primarily of genotypic constitution, but upon this are superposed fluctuations, slight or more pronounced, arising as the result of 
reaction to environmental conditions. In the extreme case the genetic machinery may, so to speak, be put out of action; genotypic potentiality no longer becomes actual. We say that the character is not inherited. We meet with such an example in Ranunculus aquatilis. According to Mer (Bull. Soc. Bot. de France, i., 27, I880), the terrestrial form of this plant has no hairs on the ends of the leaf-segments, but in the aquatic individual the segments end in needleshaped hairs-that is to say, hairs of a definite form are produced in a definite region. Again, Massart Bull. Jard. Bot. Bruxelles, i., 2, 1902) finds that in Polygonum amphibium the shoot produces characteristic multicellular hairs when exposed to the air, but if submerged it ceases to form them on the new growth. Every individual, however bred, behaves in the same manner, and must therefore have the same genetic constitution. In an atmospheric environment genotypic expression is achieved; in water it becomes physiologically impossible. A limitation to genotypic expression may in like manner be brought about by the internal environment, for the relation of the soma to the germ elements may be looked upon in this light. Thus in the case of a long-pollened and roundpollened sweet pea, Bateson and Punnett (Report to the Evolution Committee, Roy. Soc., ii., I905) found that the $F_{1}$ pollen-grains are all long, yet half of them carry the factor for roundness. If we take the chromosome view, and if it be presumed that the factor for roundness is not segregated until the reduction division, the cytoplasm of the pollen mother-cells may be supposed to act as a foreign medium owing to a mixture of qualities having been impressed upon it through the presence of the two opposite allelo morphs before the moment of segregation. We should, consequently, infer that the round-pollen shape is produced only when the round-factor-bearing chromosome is surrounded by the cytoplasm of an individual which does not contain the long factor. If, further, we regard the result in this case as indicative of the normal interrelation of nucleus and cytoplasm in the hereditary process, we shall be led to the view that, whatever the earlier condition of mutual equilibrium or interchange between these two essential cell constituents may be, an ultimate stage is reached in which the rôle of determining agent must be assigned to the nucleus.

In conclusion, I would appeal for more organised co-operation in the experimental study of genetics. It is a not uncommon attitude to look upon the sub. ject of genetics as a science apart. But the complex nature of the problems confronting us requires that the attacking force should be a composite one, representing all arms. Only the outworks of the fortress can fall to the vanguard of breeders. Their part done, they wait ready to hand over to the cytologists, with whom it lies to consolidate the position and render our foothold secure. This accomplished, the way is cleared for the main assault. To push this home we urgently need reinforcements. It is to the physio. logists and to the chemists that we look to crown the victory. By their co-operation alone can we hope to win inside the citadel and fathom the meaning of those activities which take shape daily before our eyes as we stand without and observe, but the secret of which is withheld from our gaze.

\section{The Air Conference, I9zo.}

THIS Conference, consisting of representatives of aviation in all its many branches, lasted three days, and was organised by the Air Ministry in order to bring together persons interested in the subject in conditions under which urgent problems could be freely discussed with the knowledge that resolutions of the conference arrived at after such discussion would be welcomed by the Ministry as assisting the Secretary for Air in his endeavour to promote in every way the national interests depending on aeronautics.

At the luncheon at which he presided on the first day of the conference, Mr. Churchill, Secretary of State for War and Air, made this abundantly clear. The future of military aviation, he pointed out, depended on the widespread development of civil aviation. "We," he continued-"I am speaking for the Government-intend to help civil aviation by every means in our power. You know our resources are limited, but I hope the day is coming when it will be possible for us to increase to some extent the resources which are available for the development of civil aviation. I do not think three years should be too much to reconstruct the Air Service, so that fathers of every grade in our national life shall be glad to send their sons into it with the feeling that they are giving them a good start in life, with the possibility of a fine career."

In the main (he added), civil aviation must fly by itself, and the function of the Government would be to facilitate its action-to liberate, stimulate, and encourage its action. The Air Estimates had shortly to be considered. He excluded no solution which would be likely to help us through the two or three difficult vears ahead of us. No one could have the slightest doubt about the ultimate future. To suppose that the world, having got into the air, was ever going to get out of it, was as absurd as to suppose that the NO. 2660 , VOL. I06] world, having taken to steamships, was going back to schooners and sailing ships. They were gathered there to drive away pessimișm and to assert their view that a great and bright future was opening for British aviation.

The conference was held, by the courtesy of the Lord Mayor, in the council chamber of the Guildhall on October I2, I3, and I4, and the room was well filled during all the sessions. The Lord Mayor himself welcomed the members, and in a few well chosen words expressed his sense of the importance of the occasion. He then gave place to Lord Montagu of Beaulieu, whose interest in aviation is known to all. On the second day Lord Weir of Eastwood, President of the Air Council during a most critical part of the war, presided; while on the third day the chairmen were, in the morning, Lord Beatty and, in the afternoon, Lord Londonderry, Under-Secretary of State, for Air, who had been detained in Ireland and was unable, in consequence, to be present at the opening sessions.

The business details were admirably arranged. A paper was read by some recognised authority on the subject under discussion, one or two invited speakers followed, and then the discussion was open to all who cared to contribute.

The conference was fortunate in that three out of the six papers were read by the members of the Air Council responsible for the subjects considered, while other members of the Council took part in the discussion. The audience thus learnt at first hand official views on these matters.

The conference was widely representative; invitations had been sent not onlv to airmen, to designers and builders of aircraft of all kinds, and to the representatives of aeronautical organisations, but also to the Air Attachés of foreign Powers, to members of 